Veer, A.J.E. de, Francke, A.L., Struijs, A., Willems, D.L. Determinants of moral distress in daily nursing practice: a cross sectional correlational questionnaire survey. International Journal of Nursing Studies: 2013, 50(1), 100-108

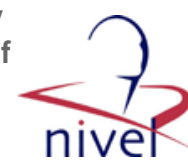

\begin{tabular}{|l|l|}
\hline $\begin{array}{l}\text { Postprint } \\
\text { Version }\end{array}$ & 1.0 \\
\hline Journal website & http://linkinghub.elsevier.com/retrieve/pii/S0020-7489(12)00290-8 \\
\hline Pubmed link & $\underline{\text { http://www.ncbi.nlm.nih.gov/pubmed/22989404 }}$ \\
\hline DOI & $10.1016 /$ j.jnurstu.2012.08.017
\end{tabular}

This is a NIVEL certified Post Print, more info at http://www.nivel.eu

\title{
Determinants of moral distress in daily nursing practice: A cross sectional correlational questionnaire survey
}

\author{
AnKe J.E. De Veer ${ }^{\mathrm{A}, *}$, ANNEKe L. FrancKe ${ }^{\mathrm{A}, \mathrm{B}}$, Alies STRUiJS ${ }^{\mathrm{C}, \mathrm{D}}$, DicK L. Willems ${ }^{\mathrm{D}, \mathrm{E}}$ \\ ${ }^{a}$ The Netherlands Institute for Health Services Research (NIVEL), P.O. Box 1568, 3500 BN \\ Utrecht, The Netherlands \\ ${ }^{\mathrm{b}}$ Department of Public and Occupational Health, EMGO Institute for Health and Care \\ Research (EMGO+) of the VU University Medical Center Amsterdam, The \\ Netherlands \\ ${ }^{c}$ Centre for Ethics and Health (CEG), P.O. Box 19404, 2500 CK The Hague, The \\ Netherlands \\ ${ }^{d}$ Council for Public Health and Health Care, P.O. Box 19404, 2500 CK The Hague, The \\ Netherlands \\ e Academic Medical Center University of Amsterdam, Department of General Practice/Family \\ Medicine, P.O. Box 22660, 1100 DD Amsterdam, The Netherlands
}

\begin{abstract}
A B S T RA C T
Background: Moral distress is associated with job dissatisfaction, turnover and early retirement. Because of these negative consequences moral distress should be reduced. Little research has been done on what job factors contribute to whether or not a situation causes moral distress.

Objective: To identify individual and job characteristics associated with moral distress in nursing staff.

Design: This is a cross sectional correlational study. Nursing staff members completed two survey questionnaires with a time-interval of 3 months. In the first survey questions were asked about job characteristics and job satisfaction. Three months afterwards the respondents answered questions on moral distress. Participants: 365 nursing staff members employed in nursing homes, homes for the elderly, home care and acute care hospitals completed both questionnaires. Results: High moral distress levels were related to lower job satisfaction. Moral distress is higher when nurses perceive less time available to give care to patients. If satisfaction with the consultation possibilities within the team is low and when an instrumental leadership style exists, nursing staff members are also
\end{abstract}


Veer, A.J.E. de, Francke, A.L., Struijs, A., Willems, D.L. Determinants of moral distress in daily nursing practice: a cross sectional correlational questionnaire survey. International Journal of Nursing Studies: 2013, 50(1), 100-108

more likely to experience moral distress. Nursing staff members working 30-40 $\mathrm{h}$ per week experience less moral distress than colleagues working fewer hours per week. Multivariate analyses showed no relations with other individual characteristics measured.

Conclusion: Job characteristics that contribute to moral distress should be an issue for managers because it is related to job satisfaction. Interventions to reduce moral distress should target at organisational issues. The way a team is supported can raise or decrease moral distress levels.

What is already known about the topic?

- Nursing staff report more moral distress due to changes in staffing, higher societal demands, and changes in the health care system.

- Moral distress is often mentioned in association with job satisfaction, burnout, and nurse turnover, but there are still limited empirical data that support these associations.

- Most previous research concentrates on nurses in hospitals.

What this paper adds

- Moral distress predominantly arises when giving care to patients and is associated with job satisfaction.

- The extent to which a situation leads to moral distress is determined by the organisational context. Time pressure, consultation opportunities with colleagues and leadership style are related to the amount of moral distress a situation triggers.

- The results are applicable to different health care settings, including nursing homes and home care.

\section{INTRODUCTION}

Moral distress consists of negative stress symptoms that occur in situations that involve ethical dimensions and where the nurse feels (s)he is not able to preserve all interests and values at stake (Kälvemark et al., 2004). Changes in the health care system leading to, for instance, an increased number of legal rules, clinical guidelines and protocols, a strong emphasis on accountability, inadequate staffing and job pressure and higher societal demands have been associated with more moral distress (Table 1, Ulrich et al., 2003). Health care organisations may aim to reduce moral distress by helping employees to adequately deal with ethical dilemmas. The objective of this research is to determine individual and job characteristics that are related to moral distress experiences of nursing staff. 
Veer, A.J.E. de, Francke, A.L., Struijs, A., Willems, D.L. Determinants of moral distress in daily nursing practice: a cross sectional correlational questionnaire survey. International Journal of Nursing Studies: 2013, 50(1), 100-108

\section{[TABLE 1]}

\subsection{Moral distress and consequences}

Jameton (1984) is often cited as the philosopher and ethicist who introduced the concept of moral distress into nursing practice (e.g. [Corley et al., 2001], [Corley et al., 2005] and [Pendry, 2007]). According to Jameton moral distress is the painful psychological disequilibrium that results from recognising an ethically appropriate action that is difficult to take because of institutional obstacles such as a lack of time, supervisory reluctance, an inhibiting medical power structure, institutional policy, or legal considerations (Corley et al., 2001). In practice, however, health care workers did not always know the ethically appropriate action (as Jameton suggested), and yet experienced moral distress (Kälvemark et al., 2004). For instance, they also experienced moral distress when they had to make difficult choices between institutional rules and what they thought was morally right. Kälvemark et al. therefore suggested a broader definition of moral distress referring to negative stress symptoms that occur due to situations that involve ethical dimensions and where the health care provider feels not to be able to preserve all interests at stake. So individual and structural factors play a role in moral distress (Pauly et al., 2012). It is meaningful to distinguish moral distress from emotional distress and other kinds of distress (McCarthy and Deady, 2008). A nurse may, for example, be emotionally distressed while restraining a patient, but is likely to become morally distressed only if the nurse believes that restraining the patient is morally wrong. Similarly a nurse may be stressed because of long working hours but is likely to become morally distressed only when worrying that this impacts negatively on the quality of care. This requires moral reflection, reasoning, and agency. In the literature there is a controversy about the actual meaning of moral distress and to which it is an accurate presentation of wrong doing (see for example Repenshek, 2009). A further elaboration of this controversy is beyond the scope of our study.

Nurses associate moral distress with feelings of frustration, anger and guilt (Wilkinson, 1988). Moral distress affects both their personal life, for example, causing short temper and irritability, and their professional life, for example, leading to difficulty in concentrating, and feelings of ineffectiveness (McClendon and Buckner, 2007). Moral distress is often mentioned in association with decreased job satisfaction, burnout, and nurse turnover (e.g. [Hart, 2005], [Meltzer and Huckabay, 2004] and [Pendry, 2007]), but there still are limited empirical data that reliably support these assertions (Schluter et al., 2008).

\subsection{Individual characteristics and their relationship to moral distress}

No relationships were found between moral distress and gender (e.g. [Corley et al., 2001], [Elpern et al., 2005] and [Meltzer and Huckabay, 2004]) and religion ( [Meltzer and Huckabay, 2004] and [Van der Arend and Remmers-Van den Hurk, 1999]). The relationship with age is not clear, with studies finding negative (e.g. [Corley et al., 2005] and [Kälvemark Sporrong et al., 2006]), positive (e.g. Rice et al., 2008) and no relationship between age and moral distress (e.g. [Corley et al., 2001], [Elpern et al., 2005] and [Meltzer and Huckabay, 2004]). Mixed results were also found in research on the relationship between moral distress and years of 
Veer, A.J.E. de, Francke, A.L., Struijs, A., Willems, D.L. Determinants of moral distress in daily nursing practice: a cross sectional correlational questionnaire survey. International Journal of Nursing Studies: 2013, 50(1), 100-108

professional experience and educational level (e.g. [Corley et al., 2001], [Corley et al., 2005], [Elpern et al., 2005] and [Meltzer and Huckabay, 2004]).

It is concluded that in the available studies moral distress seems not to be related to gender or religion, whereas the relationship with age, years of experience and educational level is still not clear. However, most research on moral distress is descriptive, and still limited knowledge exists about determinants of moral distress.

\subsection{Job characteristics and their relationship to moral distress}

There are indications that some health care settings more easily trigger moral distress than other settings. Corley et al. (2001) did not find differences in moral distress levels between different kinds of hospitals, but there are some studies that did find a relationship between health care setting and moral distress. Within a hospital, nurses who cared for oncology and transplant patients experienced more moral distress than other nurses (Rice et al., 2008). Community nurses were found to report less moral distress than hospital nurses (Eizenberg et al., 2009) or nurses in psychiatric hospitals (Van der Arend and Remmers-Van den Hurk, 1999).

Few researchers also looked at possible influences of the work environment. Based on a literature review of moral problems experienced by nurses in terminal care, Georges and Grypdonck (2002) concluded that because of a lack of autonomy, nurses are sometimes unable to act in accordance with their own values, which causes moral distress.

There is also evidence that moral distress is influenced by peer support (Schluter et al., 2008), supervision (Magnussen et al., 2002), and ethical climate, that is the nursing staffs' perception of the way in which the organisation views and handles ethical issues ( [Corley et al., 2005] and [Pauly et al., 2009]).

\subsection{Aim}

So far research on moral distress has often been focussed on what moral distress is, the prevalence of moral distress, and possible individual determinants. Little research has been done on what job characteristics contribute to whether or not a situation causes moral distress and further investigation of the ways job factors contribute to moral distress is needed (Pauly et al., 2009).

The aim of this study was twofold. First, to give insight into nurses' moral distress in several work settings, in acute as well as chronic care and in inpatient as well as outpatient care. Most previous research on moral distress concentrates on nurses in hospitals, working in acute care or critical care settings (e.g. [Corley et al., 2001], [Corley et al., 2005], [Elpern et al., 2005], [McClendon and Buckner, 2007], [Meltzer and Huckabay, 2004], [Mobley et al., 2007] and [Rice et al., 2008]). The second aim was to explore individual as well as job characteristics that influence moral distress.

The questions were:

1. What kinds of situations are likely to trigger moral distress?

2. .Is intensity of moral distress related to job satisfaction?

3. Which individual and job characteristics are associated with intensity of moral distress? 
Veer, A.J.E. de, Francke, A.L., Struijs, A., Willems, D.L. Determinants of moral distress in daily nursing practice: a cross sectional correlational questionnaire survey. International Journal of Nursing Studies: 2013, 50(1), 100-108

\section{METHODS}

\subsection{Design and setting}

This cross sectional correlational study was based on two datasets:

(1) a dataset on individual characteristics and job characteristics of nurses, gathered in the Netherlands in June 2009;

(2) a dataset on the frequency and intensity of moral distress, gathered in September 2009.

It was a secondary analysis since the data on individual and job characteristics were originally not gathered to explain moral distress.

\subsection{Sample}

A total of 365 Dutch nursing staff members completed the questionnaires of both datasets. All respondents were members of the Nursing Staff Panel, consisting of a nationally representative group of nursing staff members who gave direct patient care and were willing to answer questions about their job on a regular basis. Selection of members has been made in such a way that the age and sex of the members correspond to the age and sex of the population of nursing staff. Respondents worked in nursing homes $(n=69)$, homes for the elderly $(n=79)$, home care $(n=120)$ and (acute care) hospitals $(n=97)$ throughout the Netherlands. They answered both questionnaires on the job characteristics (66\% response rate) and moral distress (62\% response rate). The vast majority of respondents were female (94\%). The average age of 48 (SD 8 years) was higher than the average age of the Dutch population of nursing staff. Most respondents (91\%) delivered direct patient care exclusively, while $9 \%$ were also involved in management tasks. The respondents were employed for $23 \mathrm{~h}$ a week on average (SD $8 \mathrm{~h}$ ) and had been working in care for an average of 22 years (SD 9 years). The distributions of these individual characteristics are also shown in Table 3.

\subsection{Measures}

\subsubsection{Moral distress}

The moral distress questionnaire has been constructed by the researchers to measure the intensity of moral distress within daily care in different health care settings. The questionnaire consisted of a list of morally distressing situations. For the construction of the questionnaire several steps were undertaken. The morally distressing situations were derived from six qualitative group interviews with about 100 nursing staff members working in nursing homes, homes for the elderly, home care and hospitals. In the interviews situations that frequently occur in daily nursing practice and cause moral distress were explored (Struijs and Van de Vathorst, 2009). The interviews had an open character and focussed on the morally distressing situations nursing staff encounter, as well as the causes and possible solutions of these situations. This resulted in a list of morally distressing situations in daily nursing practices. A scan of the international literature was also carried out to study the content of questionnaires used to measure moral distress or closely related concepts, with a view to adding items that were not yet generated from the interviews ( [Corley et al., 2001], [Corley et al., 2005], [Eizenberg et al., 2009], [Glasberg et al., 2006], [Kälvemark Sporrong 
Veer, A.J.E. de, Francke, A.L., Struijs, A., Willems, D.L. Determinants of moral distress in daily nursing practice: a cross sectional correlational questionnaire survey. International Journal of Nursing Studies: 2013, 50(1), 100-108

et al., 2006] and [Van der Arend and Remmers-Van den Hurk, 1999]). This step resulted in no additional items.

The content validity of the questionnaire was judged by five persons: a registered nurse (RN) specialised in nursing ethics, an RN specialised in nursing research, and three experts in ethics within health care. As a result of this phase one item was added, which resulted in a pool of 24 items with 4-point Likert type answers ( 1 = not distressing, 4 = very distressing). To further validate the questionnaire, the nurses who responded to the questionnaire were also asked to rate the frequency of occurrence of each situation. Since the questionnaire was intended to measure the intensity of moral distress in daily practice, rarely occurring situations should be omitted from the questionnaire. A 5-point Likert scale was used to measure the frequency of occurrence: daily, weekly, monthly, less than monthly, (almost) never. All but 1 item were recognised by at least half of the respondents as occurring in daily practice. In reaction to the item "I don't agree with a particular end-of-lifedecision concerning treatment policy that has been made. What do I do?" more than half of the respondents in each health care sector answered that this situation (almost) never took place. Therefore this item was eliminated.

The coefficient Cronbach's alpha of 0.90 showed that the remaining 23 items formed an internally consistent scale. The average score of the respondents was 2.18 (SD

0.52 , range $1.00-3.57)$. The scores of the respondents were normally distributed (test skewness $\mathrm{p}=.765$, test kurtosis $\mathrm{p}=.136$, tested jointly $\mathrm{p}=.3136$ ).

\subsubsection{Job satisfaction}

Job satisfaction was measured with a shortened version of the MAS-GZ

(Landeweerd et al., 1996) and consisted of seven subscales measuring aspects of job satisfaction such as contacts with colleagues, contacts with patients, consultation possibilities, personal growth and leadership. Each subscale consisted of three items on a 5-point Likert scale ranging from very dissatisfied to very satisfied. Overall job satisfaction was the mean score of all 21 items (Cronbach's alpha $=.90$ ).

Job satisfaction was also measured with one item on an 11-point Likert scale ranging from "my job is the worst possible job" (0) to "my job is the best possible job" (10).

\subsection{Job characteristics}

All job characteristics have been measured by means of validated scales or single items (De Veer et al., 2010). Table 4 shows an overview of the characteristics of the variables.

- -Job related stress was operationalised as the satisfaction with the time available to give care to patients (developed by Ruijters and Stevens (1992)). An example of the five items was "I have enough time to give good care to patients" followed by a 5-point Likert scale ranges from 'I fully disagree' to 'I fully agree' (Cronbach's alpha $=.84$ ).

- -Job load. Respondents were asked to indicate how often (1) they did overtime work and (2) skipped breaks. A 5-point Likert scale was used to 
Veer, A.J.E. de, Francke, A.L., Struijs, A., Willems, D.L. Determinants of moral distress in daily nursing practice: a cross sectional correlational questionnaire survey. International Journal of Nursing Studies: 2013, 50(1), 100-108

measure a frequency ranging from 'rarely' to 'very often' (Cronbach's alpha $=.70)$.

- -Perceived quality of care. Two questions concerned the perceived quality of care provided by the team the respondent belongs to. The first question was a general assessment of the quality of care ranging from bad to very good (5point Likert scale). The second question concerned the frequency with which poor-quality care was provided (5-point Likert scale ranging from often to never). The perceived quality of care was the average of both answers (Cronbach's alpha $=.76$ ).

- - Trust in other professionals was operationalised as three separate questions: How much trust do you have in the expertise of (a) colleagues (b) doctors, and (c) your team manager. Possible answers ranged from very little to very high (5-point Likert scale).

- -Autonomy was considered as a unidimensional construct and was measured by the VBBA, a questionnaire for the perception and evaluation of work, developed by Van Veldhoven and Meijman (1994). The VVBA scales are the most reliable, valid and sensitive scales available in Dutch for measuring work related outcomes. Example of the 11 items were "Can you determine the order of your work?" and "Do you solve problems yourself?" (never/sometimes/often/always). Cronbach's alpha of this scale was .91.

- -Leadership referred to the perceptions of nursing staff of the way they were managed by the team manager. The leadership questionnaire (Stogdill, 1963, translated by Boumans, 1990) measured two dimensions of leadership behaviour: supportive leadership (the manager is employee oriented and considerate of the needs of the team members, is friendly and approachable) and instrumental leadership (the actions are directed at clarifying expectations and goals and completing tasks). The subscales consisted of 11 and 9 behaviours with answers ranging from never to always (5-point Likert scale, Cronbach's alphas were .91 and .82).

Satisfaction with opportunities to consult with colleagues was measured by one item: "How satisfied or dissatisfied are you with the consultation possibilities within your team?" with five possible answers ranging from very dissatisfied to very satisfied.

- -Finally, satisfaction with patient contact and satisfaction with possibilities for personal growth were two subscales of the above-mentioned job satisfaction questionnaire.

\subsection{Ethical considerations}

As this was a questionnaire-based study of nursing staff and had no patient involvement, approval from an ethics committee is not required in the Netherlands. Study participation was voluntary. Responses were anonymous and non-traceable to individual nurses. 
Veer, A.J.E. de, Francke, A.L., Struijs, A., Willems, D.L. Determinants of moral distress in daily nursing practice: a cross sectional correlational questionnaire survey. International Journal of Nursing Studies: 2013, 50(1), 100-108

\subsection{Data analysis}

The data were analysed using Stata 10.0. Descriptive statistics were performed to describe the moral distress nurses experience when confronted with a particular situation. Analyses of variance (for categorically independent variables) and Pearson product moment correlations (for independent variables at interval level) were conducted to explore bivariate relationships between individual and job variables and intensity of moral distress. A multivariate stepwise regression analysis was conducted to examine what variables best predict intensity of moral distress. All bivariate relations with a $\mathrm{p}<.05$ were included in this analysis.

\section{RESULTS}

\subsection{Morally distressing situations}

Table 2 shows ten situations with the highest mean scores on intensity of moral distress. The most morally distressing situation occurred when a discrepancy was perceived between the wishes of the family and patient. Also the treatment policy of doctors triggered considerable moral distress if the nurse did not agree with it or perceived that the policy was not in accordance with what the patient wanted. Other items reflected the sense of responsibility the nursing staff member had towards the general functioning of the team (e.g. if a colleague did not function properly or made a mistake, or there was inadequate staffing). Finally, there were three situations that may arise while the nursing staff member is giving direct patient care. Nursing staff members experienced high moral distress when caring for a patient if they discovered that they were not aware of the agreements that had been made about the care. When the patient asked about medical information the nurse was (legally) not allowed to give, this also triggered moral distress. In general, nursing staff members struggled with the discrepancy between officially indicated care and the care the patient actually needed, according their own professional standard.

\section{[TABLE 2]}

\subsection{Moral distress and job satisfaction}

Our second question concerned the relationship between the degree to which situations triggered moral distress and general job satisfaction. Pearson product moment correlation coefficients showed that nursing staff who were less satisfied with their job $(r=-.34, \mathrm{p}<.000)$ and gave lower general grading scores for their job $(\mathrm{r}=-.28, \mathrm{p}<.000)$ had higher moral distress scores.

\subsection{Bivariate relationships between individual characteristics and intensity of moral distress}

No statistically significant relationships were found between age $(r=-.03, p=.546$, not in table), gender, years of experience, job position and intensity of moral distress (Table 3).

\section{[TABLE 3]}

Weak, but statistically significant relationships were found with educational level and number of employment hours (Table 3). Nursing staff with an associate level of qualification generally had higher moral distress scores than RNs. Nursing staff 
Veer, A.J.E. de, Francke, A.L., Struijs, A., Willems, D.L. Determinants of moral distress in daily nursing practice: a cross sectional correlational questionnaire survey. International Journal of Nursing Studies: 2013, 50(1), 100-108

working at least $30 \mathrm{~h}$ per week showed lower moral distress scores than nursing staff working fewer hours per week.

\subsection{Bivariate relationships between job characteristics and intensity of moral distress}

Differences were found in mean moral distress scores between health care sectors (Table 3). Nursing staff in nursing homes had the highest scores and this was statistically significantly higher than those in home care, which had the lowest mean. Table 4 shows that trust in colleagues was not related to moral distress. All the other characteristics were statistically significantly related to moral distress scores. Job related stress showed the strongest relationship, followed by perceived quality of care, satisfaction with possibilities of growth, satisfaction with opportunities with colleagues, autonomy and instrumental leadership $(r>.20, p<.001)$. Nursing staff members who reported not to have sufficient time available for their patients reported higher moral distress levels. Moral distress was also more intense when the nursing staff member perceived the quality of care provided by the team as relatively low. Nursing staff members who were less satisfied with personal growth opportunities and with the opportunities to consult colleagues experienced higher moral distress. Furthermore, nursing staff members experiencing low professional autonomy and a higher level of instrumental leadership reported more intense moral distress. The other characteristics all had weaker, but statistically significant, correlations with intensity of moral distress.

\section{[TABLE 4]}

\subsection{Possible determinants of intensity of moral distress}

Multivariate regression analysis showed that four variables explained 21\% of the variance of moral distress scores (Table 5). Nursing staff members with part-time jobs, higher job related stress levels, less satisfaction with opportunities to consult with colleagues and perceiving higher levels of instrumental leadership experienced more moral distress. Further exploration of the intercorrelations between the job characteristics and alternative regression models showed that high job related stress levels related to lower perceived quality of care $(r=.55, \mathrm{p}<.001)$, while opportunities to consult with colleagues related to satisfaction with possibilities of personal growth $(r=.43, \mathrm{p}<.001)$. Each variable could be replaced by its related variable in the regression analysis, although the explained variance within moral distress became lower.

\section{[TABLE 5]}

\section{DISCUSSION AND CONCLUSION}

\subsection{Strengths and weaknesses of this study}

In this study the intensity of moral distress has been measured that may occur when nursing staff members have to deal with a number of interests and values in daily care. This study is one of the first to examine job determinants of moral distress. Another strength of this study is that the intensity of moral distress in different health 
Veer, A.J.E. de, Francke, A.L., Struijs, A., Willems, D.L. Determinants of moral distress in daily nursing practice: a cross sectional correlational questionnaire survey. International Journal of Nursing Studies: 2013, 50(1), 100-108

care settings has been studied. There is only a small amount of research done on long term care, such as nursing homes and home care and from this viewpoint this research adds new information in relation to this. Furthermore, the 3 months timeinterval between the measurement of job characteristics and the measurement of moral distress strengthens the results of this study because the experienced intensity of moral distress is not likely to be influenced by perceptions of job characteristics. Since it was a secondary exploratory analysis we did not have information about determinants that, from a theoretical viewpoint, might probably better explain moral distress. There is, for example, evidence that moral distress is related to moral reasoning style and coping style (Raines, 2000) and to ethical climate (e.g. Pauly et al., 2009). In our study we used a self developed questionnaire to measure the intensity of moral distress within daily care and, as a result, the evidence for the construct validity of the questionnaire is limited. Studying the relationship of these concepts with the intensity of moral distress could further validate the moral distress questionnaire we used.

\subsection{Situations triggering moral distress}

Situations experienced as most morally distressing arise within the caring process and in the relationship between nurse, patient, family and doctor. The highest level of moral distress is triggered by situations that involve complying with families' wishes for patient care even though the patient disagrees, complying with the physician even though the nurse disagrees, and working with staffing levels perceived as unsafe. Similar results were found in other research (Zuzelo, 2007). These morally distressing situations are different from ethical dilemmas that address the question:

'What is good care in this situation?'. Morally distressing situations relate to the question: 'How should I deal with all interests and values at stake?'. In the situations triggering moral distress the nurse knows what good care is but cannot act accordingly for various reasons. Moral distress consists of feelings of powerlessness, subordination and inefficiency, but also leads to passivity and blunted moral sensitivity. This is especially true if the moral distress remains unresolved. The moral residue, as Webster and Baylis (2000) described the possible consequence of unresolved moral distress, may have a significant impact on nursing staff. Accumulation can result in negative effects such as job dissatisfaction. Our study confirms that the intensity of perceived moral distress is associated with job satisfaction, which is not a desirable outcome because it is associated with staff turnover ( [Coomber and Barriball, 2007] and [Hayes et al., 2011]).

Can and should moral distress be eliminated? Some form of moral tension is probably inevitable in health care - it is obviously not always possible to provide care according to one's own ideals. One could even argue that a degree of moral tension may improve the quality of care, because it maintains a certain sensitivity to moral issues in everyday care. However, professionals with the highest standards regarding good care are logically more prone to moral distress, and these may be the kind of professionals that are most needed. If moral tension becomes moral distress, quality of care will be jeopardised because the suffered may undermine the intrinsic motivation of individuals to provide good care ( [Deci et al., 1999], [Gardner et al., 
Veer, A.J.E. de, Francke, A.L., Struijs, A., Willems, D.L. Determinants of moral distress in daily nursing practice: a cross sectional correlational questionnaire survey. International Journal of Nursing Studies: 2013, 50(1), 100-108

2010] and [Koehn, 1994]). Therefore, we conclude that the intensity of moral distress should be reduced as much as possible.

\subsection{Addressing moral distress}

Given that high levels of moral distress are associated with job dissatisfaction, burnout and nurse turnover ( [Corley et al., 2001], [Corley et al., 2005], [Elpern et al., 2005], [Meltzer and Huckabay, 2004] and [Pendry, 2007]) health care institutions and professionals should consider ways to reduce the intensity of moral distress. Several implications for nursing practice result from this study.

Firstly, nurses who feel that they do not have enough time for patient care are likely to become more morally distressed. Perceived time pressure makes it more likely that a nurse starts to worry about the quality of care (s)he is able to give. Moral distress arises if (s)he wants to give good quality care but feels impeded from doing so because time is running out. There is empirical evidence that time pressure in Dutch nursing care is increasing (De Veer and Francke, 2010). In such pressing daily practice, moral issues are often ignored, and neither identified nor discussed. Dealing with moral issues is not solely a personal issue ('me and my conscience'), but is also a social one (Catlin et al., 2008). If ethical issues are never discussed, a care provider needs to have strong convictions to raise them anyway. Nursing staff members are generally reticent in this respect. A sense of having reached the limits of acceptable care could also lead to a great moral debate within health care institutions but also at a national level. The absence of such a debate appears to be caused by a lack of professional self-respect (Struijs and Van de Vathorst, 2009). This creates a vicious circle: the lack of a sense of being appreciated leads to care impoverishment and a hollowing out of the profession, leading to low self-respect, which in turn leads to more lack of appreciation. And lack of appreciation in turn contributes to staffing shortages. Empowering nurses to practice to professional standards and to use their knowledge and expertise may break this vicious circle ( [Laschinger et al., 2006], [Lautizi et al., 2009] and [Lu et al., 2011]). Health care institutions can stimulate the debate and should stand up for good (quantitative as well as qualitative) staffing. Secondly, this study shows that nursing staff members may benefit from being able to talk and reflect with other nurses about the problems they face. To support nurses in their efforts to deal with daily problems, to recognise the moral aspects, and to reduce the related stress, managers should create opportunities that encourage nurses to talk with colleagues and to discuss their views on the situation. Encouraging nurses to share their ethical concerns can empower them to deal better with difficult situations and emotions ( [Bégat et al., 2005] and [Pauly et al., 2009]).

Thirdly, the results show that certain leadership behaviours may affect moral distress. However, we found a bivariate relationship between supportive leadership and moral distress, but since supportive leadership and satisfaction with consultation opportunities are positively correlated this relationship disappeared in the multivariate analysis. Instrumental behaviours are found to trigger moral distress. Some managers try to implement management in an instrumental way by, for example, focussing on tasks, setting boundaries, standards, and formulating targets. At times such policies can be too rigid. Leadership styles focussing on people and relationships are found to relate to higher job satisfaction whereas styles focussing on 
Veer, A.J.E. de, Francke, A.L., Struijs, A., Willems, D.L. Determinants of moral distress in daily nursing practice: a cross sectional correlational questionnaire survey. International Journal of Nursing Studies: 2013, 50(1), 100-108

tasks relate to lower job satisfaction (Cummings et al., 2010). This supports the hypothesis that leadership style buffers the intensity of moral distress.

Finally, nursing staff members with part-time jobs show higher moral distress levels. This finding is surprising in that it could be hypothesised that nursing staff members working part time are less stressed than those working full time. Full time personnel may have more knowledge of ethics or may have developed a more pragmatic approach in dealing with situations that trigger moral distress. Alternatively, parttime staff members are less immersed in a culture of a team or organisation and are therefore better able to perceive poor ethical practice. Alternatively, many part-time staff members may prefer a (more) full-time position, that is not available. If this is the case organisations should create more full-time positions. It is interesting to qualitatively investigate the mechanisms that play a role here.

\subsection{Conclusion}

This study shows that moral distress predominantly arises when giving care to patients, and since it is closely related to job satisfaction it is important to investigate ways in which high levels of moral distress can be avoided. The extent to which a situation leads to moral distress is not clearly related to individual characteristics but is determined by the organisational context. Time pressure, consultation opportunities with colleagues and leadership style are related to the amount of moral distress a situation triggers. Interventions to reduce moral distress should target at these issues.

Author's contributions: Anke de Veer and Anneke Francke were the principal investigators and were responsible for study concept and design, analysis, interpretation of data and preparation of the manuscript. Alies Struijs and Dick Willems were responsible for the content of the moral distress scale and wrote parts of the manuscript.

Conflict of interest: All authors disclose no financial conflict of interest.

Funding: This research was financed by the Dutch Centre for Ethics and Health, which had an advisory role in giving suggestions about the content of the moral distress scale. The Nursing Staff Panel is financed by the Dutch Ministry of Health. The Dutch Centre for Ethics and Health and the Ministry of Health have no interest in whatever directions the results are pointing to. The opinions expressed in this article are those of the authors.

Ethical approval: As this was a questionnaire-based study of nursing staff and had no patient involvement, approval from an ethics committee is not required in the Netherlands. Study participation was voluntary. Responses were anonymous and non-traceable to individual nurses.

\section{ACKNOWLEDGEMENTS}

The research on moral distress is financed by the Dutch Centre for Ethics and Health. The Nursing Staff Panel is financed by the Dutch Ministry of Health.

\section{REFERENCES}

Bégat, I., Ellefsen, B., Severinsson, E., 2005. Nurses' satisfaction with their work environment and the outcomes of clinical nursing supervision on nurses' experiences of well-being - a Norwegian study. Journal of Nursing Management 13 (3), 221-230. 
Veer, A.J.E. de, Francke, A.L., Struijs, A., Willems, D.L. Determinants of moral distress in daily nursing practice: a cross sectional correlational questionnaire survey. International Journal of Nursing Studies: 2013, 50(1), 100-108

Boumans, N., 1990. Het werk van verpleegkundigen in algemene ziekenhuizen. Een onderzoek naar werkaspecten en hun invloed op verpleegkundigen. Proefschrift. Faculteit der Gezondheidswetenschappen, Rijksuniversiteit Limburg, Maastricht.

Catlin, A., Volat, A., Hadley, M., Bassir, R., Armigo, C., Valle, E., Gong, W., Anderson, K., 2008. Conscientious objection: a potential neonatal nursing response to care orders that cause suffering at the end of life? Study of a concept. Neonatal Network 27 (2), 101-108.

Coomber, B., Barriball, K.L., 2007. Impact of job satisfaction components on intent to leave and turnover for hospital-based nurses: a review of the research literature. International Journal of Nursing Studies 44 (2), 297-314.

Corley, M.C., Elswick, R.K., Gorman, M., Clor, T., 2001. Development and evaluation of a moral distress scale. Journal of Advanced Nursing 33 (2), 250-256.

Corley, M.C., Minick, P., Elswick, R.K., Jacobs, M., 2005. Nurse moral distress and ethical work environment. Nursing Ethics 12 (5), 381-390.

Cummings, G.G., MacGregora, T., Davey, M., Lee, H., Wong, C.A., Lo, E., Muise, M., Stafford, E., 2010. Leadership styles and outcome patterns for the nursing workforce and work environment: a systematic review. International Journal of Nursing Studies 47, 363385.

De Veer, A.J.E., Francke, A.L., 2009. Morele dilemma's in het dagelijks werk van verpleegkundigen en verzorgenden. (Moral Dilemmas in Daily Work of Nursing Staff Members).NIVEL, Utrecht.

De Veer, A., Francke, A., 2010. Determinants of job related stress experi- enced by nursing staff. Journal of Clinical Nursing 19 (Suppl. 1), 111.

De Veer, A.J.E., Spreeuwenberg, P., Francke, A.L., 2010. De aantrekkelijkheid van het verpleegkundig en verzorgend beroep. Cijfers en trends. (The Attractiveness of the Nursing and Caring Profession. Numbers and Trends).NIVEL, Utrecht.

Deci, E.L., Koestner, R., Ryan, R.M., 1999. A meta-analytic review of experiments examining the effects of extrinsic rewards on intrinsic motivation. Psychological Bulletin 125, 627-668.

Eizenberg, M.M., Desivilya, H.S., Hirschfeld, M.J., 2009. Moral distress questionnaire for clinical nurses: instrument development. Journal of Advanced Nursing 65 (4), 885-892.

Elpern, E.H., Covert, B., Kleinpell, R., 2005. Moral distress of staff nurses in an medical intensive care unit. American Journal of Critical Care 14, 523-530.

Gardner, H., Csikszentmihalyi, M., Damon, W., 2010. Good Work: When Excellence and Ethics Meet. http://www.goodworkproject.org/pub- lication/goodwork-theory-and-practice/

Georges, J.J., Grypdonck, M., 2002. Moral problems experienced by nurses when caring for terminally ill people: a literature review. Nursing Ethics 9 (2), 155-178.

Glasberg, A.L., Eriksson, S., Dahlqvist, V., Landahl, E., Strandberg, G., Soderberg, A., Sorlei, V., Norberg, A., 2006. Development and initial validation of the stress of conscience questionnaire. Nursing Ethics 16 (6.), http://dx.doi.org/10.1177/0969733006069698.

Hart, S.E., 2005. Hospital ethical climates and registered nurses' turnover intentions. Journal of Nursing Scholarship 37 (2), 173-177.

Hayes, L.J., O’Brien-Pallas, L., Duffield, C., Shamian, J., Buchan, J., Hughes, F., Spence Lanschinger, H.K., North, N., 2011. Nurse turnover: a literature review-an update. International Journal of Nursing Studies 48 (Epub ahead of print).

Jameton, A., 1984. Nursing Practice: The Ethical Issues. Prentice-Hall, London. Ka“ Ivemark, S., Ho“" glund, A.T., Hansson, M.G., Westerhom, P., Arnetz, B., 2004. Living with conflictsethical dilemmas and moral distress in the health care system. Social Science \& Medicine 58, 1075-1084.

Ka“ Ivemark Sporrong, S., Ho“ glund, A.T., Arnetz, B., 2006. Measuring moral distress in pharmacy and clinical practice. Nursing Ethics 13 (4), 416-427.

Koehn, D., 1994. The Ground of Professional Ethics. Routledge, London/ NY. Landeweerd, J.A., Boumans, N.P.G., Nissen, J.M.J.F., 1996. Arbeidsvoldoening bij verplegenden en verzorgenden. De Maastrichtse arbeidssatis- factieschaal voor de gezondheidszorg. In: Handboek verpleegkundige innovatie, pp. D250-1-D250-26.

Laschinger, H.K., Wong, C.A., Greco, P., 2006. The impact of staff nurse empowerment on person-job fit and work engagement/burnout. Nursing Administration Quarterly 30 (4), 358-367. 
Veer, A.J.E. de, Francke, A.L., Struijs, A., Willems, D.L. Determinants of moral distress in daily nursing practice: a cross sectional correlational questionnaire survey. International Journal of Nursing Studies: 2013, 50(1), 100-108

Lautizi, M., Laschinger, H.K., Ravazzolo, S., 2009. Workplace empower- ment, job satisfaction and job stress among Italian mental health nurses: an exploratory study. Journal of Nursing Management 17 (4), 446-452.

Lu, H., Barriball, K.L., Zhang, X., While, A.E., 2011. Job satisfaction among hospital nurses revisited: a systematic review. International Journal of Nursing Studies 48 (Epub ahead of print).

Magnussen, A., Lu" tze' n, K., Severisson, E., 2002. The influence of clinical supervision on ethical issues in home care of people with mental illness in Sweden. Journal of Nursing Management 10, 37-45.

McCarthy, J., Deady, R., 2008. Moral distress reconsidered. Nursing Ethics 15, 254-262.

McClendon, H., Buckner, E.B., 2007. Distressing situations in the intensive care unit. A descriptive study of nurses' responses. Dimension Critical Care Nursing 26 (5), 199-206.

Meltzer, L.S., Huckabay, L.M., 2004. Critical care nurses' perceptions of futile care and its effect on burnout. American Journal of Critical Care 13 (3), 202-208.

Mobley, M.J., Rady, M.Y., Verheijde, J.L., Patel, B., Larson, J.S., 2007. The relationship between moral distress and perception of futile care in the critical care unit. Intensive and Critical Care Nursing 23, 256-263.

Pauly, B., Varcoe, C., Storch, J., Newton, L., 2009. Registered nurses' perceptions of moral distress and ethical climate. Nursing Ethics 16 (5), 561-573.

Pauly, B., Varcoe, C., Storch, J., 2012. Framing the issues: moral distress in health care. HEC Forum 24, 1-11.

Pendry, P.S., 2007. Moral distress: recognizing it to retain nurses. Nursing Economics 25 (4), 217-221.

Raines, M.L., 2000. Ethical decision making in Nurses. Relationships amongst moral reasoning, coping style, and ethics stress. JONA's Healthcare Law, Ethics and Regulation 2 (1), 29-41.

Repenshek, M., 2009. Moral distress: inability to act of discomfort with moral subjectivity? Nursing Ethics 16 (6), 734-742.

Rice, E.M., Rady, M.Y., Hamrick, A., Verheijde, J.L., Pendergast, D.K., 2008. Determinants of moral distress in medical and surgical nurses at an adult tertiary care hospital. Journal of Nursing Management 16, 360-373.

Ruijters, R.F.M., Stevens, F.C.J., 1992. Organisatiestructuur, rolduidelijkheid, arbeidssatisfactie en het oordeel van verpleegkundigen over de samenwerking met artsen. Verpleegkunde 2, 106-114.

Schluter, J., Winch, S., Holzhauser, K., Henderson, A., 2008. Nurses' moral sensitivity and hospital ethical climate: a literature review. Nursing Ethics 15 (3), 304-321.

Stogdill, R.M., 1963. Manual for the Leader Behavior Description Ques- tionnaire Form XII. Bureau of Business Research, The Ohio State University, Columbus.

Struijs, A., Van de Vathorst, S., 2009. Dilemma's van verpleegkundigen en verzorgenden. (Dilemmas of Nurses and Carers).Centrum voor ethiek en gezondheid, Den Haag.

Ulrich, C.M., Soeken, K.L., Miller, N., 2003. Ethical conflict associated with managed care. Nursing Research 52 (3), 168-175.

Van der Arend, A.J.G., Remmers-Van den Hurk, C.H.M., 1999. Moral problems among Dutch nurses: a survey. Nursing Ethics 6 (6), 468-482,

http://dx.doi.org/10.1177/096973309900600603.

Van Veldhoven, M., Meijman, T., 1994. Het meten van psychosociale arbeidsbelasting met een vragenlijst: de vragenlijst beleving en beoordeling van de arbeid (VBBA). Nederlands Instituut voor Arbeid- somstandigheden, Amsterdam.

Webster, G., Baylis, F., 2000. Moral residue. In: Rubin, S.Z., Hagerstown, L. (Eds.), Margin of Error: The Ethics of Mistakes in the Practice of Medicine. University Publishing Group, pp. 217-230.

Wilkinson, J.M., 1988. Moral distress in nursing practice: experience and effect. Nursing Forum 23 (1), 16-29.

Zuzelo, P.R., 2007. Exploring the moral distress of registered nurses. Nursing Ethics 14 (3), 344-359. 
Veer, A.J.E. de, Francke, A.L., Struijs, A., Willems, D.L. Determinants of moral distress in daily nursing practice: a cross sectional correlational questionnaire survey. International Journal of Nursing Studies: 2013, 50(1), 100-108

\section{TABLES}

Table 1

Nurses' perceptions of the causes of the increasing frequency of situations leading to moral distress.

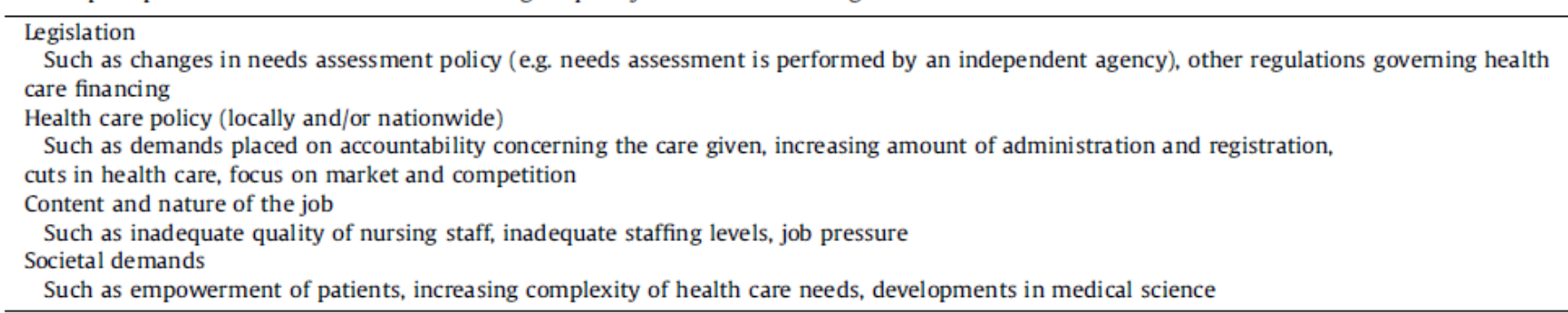
Source: De Veer and Francke (2009).

Table 2

Situations with the highest intensity of moral distress scores $(n=365)$.

\begin{tabular}{l} 
Situation \\
\hline Should I go along with relatives' wishes, even if I can tell that the client is not all that happy about this? \\
The doctor wants to do something with the client (e.g. an intervention, diagnosis or discharge \\
from care) which in my professional opinion is not good for the client at that time. What do I do? \\
I see a colleague who is not working properly. What do I do? \\
Doctor's orders differ from the client's wishes. What should I do? \\
I have the afternoon off. But then my manager calls because a colleague is sick. Do I go to work after all? \\
When I get to the client I discover I'm not sure about what has been agreed on (e.g. about the care, \\
resuscitation policy). What do I do now? \\
I have medical information that the client is not yet aware of but asks me about. Should I disclose it or not? \\
I notice that a colleague has made a mistake. What should I do? \\
Should I give my client the care that is needed according to my standards, or should I stick to the indicated care? \\
Will I stay longer to finish the work to avoid a situation of understaffing? \\
\hline
\end{tabular}


Veer, A.J.E. de, Francke, A.L., Struijs, A., Willems, D.L. Determinants of moral distress in daily nursing practice: a cross sectional correlational questionnaire survey. International Journal of Nursing Studies: 2013, 50(1), 100-108

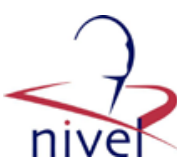

Table 3

Bivariate relationships between individual characteristics, health care sector and intensity of moral distress ( $n=365$ ).

\begin{tabular}{|c|c|c|c|c|c|}
\hline Individual characteristics & $n$ & $\%$ & Moral distress $M$ & Test statistic $F$ & $p$-Value \\
\hline \multicolumn{6}{|l|}{ Gender } \\
\hline Male & 22 & $6.0 \%$ & 2.02 & \multirow[t]{2}{*}{2.04} & \multirow[t]{2}{*}{.154} \\
\hline Female & 343 & $94.0 \%$ & 2.18 & & \\
\hline \multicolumn{6}{|l|}{ Educational level } \\
\hline NA (nurse assistant) & 198 & $54.2 \%$ & 2.24 & \multirow[t]{3}{*}{3.23} & \multirow[t]{3}{*}{$.040^{\mathrm{a}}$} \\
\hline RN, associate level degree & 105 & $28.8 \%$ & 2.10 & & \\
\hline RN, bachelor’s degree & 62 & $17.0 \%$ & 2.09 & & \\
\hline \multicolumn{6}{|l|}{ Job experience (5 missing) } \\
\hline 9 years or less & 29 & $8.1 \%$ & 2.33 & \multirow[t]{4}{*}{1.06} & \multirow[t]{4}{*}{.366} \\
\hline $10-19$ years & 106 & $29.4 \%$ & 2.17 & & \\
\hline $20-29$ years & 136 & $37.8 \%$ & 2.18 & & \\
\hline 30 years or more & 89 & $24.7 \%$ & 2.13 & & \\
\hline \multicolumn{6}{|l|}{ Job position ( 1 missing) } \\
\hline Management & 34 & $9.3 \%$ & 2.18 & \multirow[t]{2}{*}{0.89} & \multirow[t]{2}{*}{.347} \\
\hline Non-management & 330 & $90.7 \%$ & 2.09 & & \\
\hline \multicolumn{6}{|c|}{ Number of hours employed per week ( 3 missing) } \\
\hline Less than $20 \mathrm{~h}$ & 105 & $29.0 \%$ & 2.22 & \multirow[t]{3}{*}{3.64} & \multirow[t]{3}{*}{$.027^{\mathrm{b}}$} \\
\hline $20-30 \mathrm{~h}$ & 160 & $44.2 \%$ & 2.23 & & \\
\hline $30 \mathrm{~h}$ or more & 97 & $26.8 \%$ & 2.06 & & \\
\hline \multicolumn{6}{|c|}{ Health care sector (none missing) } \\
\hline Nursing homes & 69 & $18.9 \%$ & 2.31 & \multirow[t]{4}{*}{3.06} & \multirow[t]{4}{*}{$.028^{c}$} \\
\hline Homes for the elderly & 79 & $21.6 \%$ & 2.23 & & \\
\hline Home care & 120 & $32.9 \%$ & 2.10 & & \\
\hline Hospital & 97 & $26.6 \%$ & 2.12 & & \\
\hline
\end{tabular}

Table 4

Bivariate relationships between perceived job characteristics and intensity of moral distress (Pearson product moment correlation coefficients, $n=365$ ).

\begin{tabular}{|c|c|c|}
\hline Job characteristics & $r$ & p-Value (2-sided) \\
\hline Job related stress ( 5 items, $1-5$, Cronbach's alpha $=.84$ ) & .44 & .000 \\
\hline Job load ( 2 items, $1-4$, Cronbach's alpha $=.70,3$ missing) & .15 & .004 \\
\hline Quality of care ( 2 items, $1-5$, Cronbach's alpha $=.76,4$ missing) & -.31 & .000 \\
\hline Trust in colleagues ( 1 item, $1-5,4$ missing) & -.02 & .682 \\
\hline Trust in doctors ( 1 item, $1-5,9$ missing) & -.13 & .016 \\
\hline Trust in team manager ( 1 item, $1-5,5$ missing) & -.19 & .000 \\
\hline Satisfaction with contacts with patients ( 3 items, $1-5$, Cronbach's alpha $=.81,4$ missing) & -.16 & .003 \\
\hline Supportive leadership ( 11 items, $1-5$, Cronbach's alpha $=.91,6$ missing) & -.20 & .000 \\
\hline Instrumental leadership ( 9 items, $1-5$, Cronbach's alpha $=.82,7$ missing) & .23 & .000 \\
\hline Satisfaction with opportunities to consult with colleagues ( 1 item, $1-5,5$ missing) & -.27 & .000 \\
\hline Satisfaction with possibilities of growth ( 3 items, $1-5$, Cronbach's alpha $=.75,4$ missing) & -.28 & .000 \\
\hline
\end{tabular}

Table 5

Characteristics related to intensity of moral distress (stepwise multiple regression analysis, $n=332$ ).

\begin{tabular}{|c|c|c|c|c|c|}
\hline Characteristic $^{\mathrm{a}}$ & $b$ & S.E. & $\beta$ & $t$-Value & p-Value \\
\hline \multicolumn{6}{|l|}{ Number of hours employed per week } \\
\hline $20-30 \mathrm{~h}$ & & & & & n.s. \\
\hline $30 \mathrm{~h}$ and above & -.13 & .06 & -.11 & -2.30 & .022 \\
\hline Job related stress & .21 & .03 & .33 & 6.24 & .000 \\
\hline Satisfaction with opportunities to consult with colleagues & -.09 & .03 & -.11 & -2.99 & .003 \\
\hline Instrumental leadership & .10 & .04 & .15 & 2.19 & .029 \\
\hline
\end{tabular}

$R^{2}=.22$, adj. $R^{2}=.21, F(4,327)=23.22, p=.000$.

a Only statistically significant characteristics are displayed in the table. 